Article

\title{
Hard or Soft Governance? The EU's Climate and Energy Policy Framework for 2030
}

\author{
Sebastian Oberthür \\ Institute for European Studies, Vrije Universiteit Brussel, 1050 Brussels, Belgium; E-Mail: sebastian.oberthuer@vub.be
}

Submitted: 23 October 2018 | Accepted: 22 December 2018 | Published: 28 March 2019

\begin{abstract}
This article investigates the stringency of EU climate and energy governance along the soft-hard continuum as a key determinant of its ability to achieve its ambitions. It introduces four criteria for a systematic and differentiated assessment of the bindingness/stringency of legislative instruments and governance frameworks, namely: (1) formal legal status, (2) the nature of the obligations (substantive-procedural), (3) their precision and prescriptiveness, and (4) the means for effecting accountability and effective implementation. The application of this assessment framework to the EU's Climate and Energy Policy Framework for 2030 in comparison with the preceding 2020 Framework and the international Paris Agreement on climate change demonstrates the added value of this approach. The focus is on regulations, adopted in 2018, regarding greenhouse gas emissions, renewable energy (RE), and energy efficiency as well as the surrounding framework for planning, reporting, monitoring, and enforcement. The EU's 2030 Framework scores high on the four criteria. Despite implementing the comparatively soft Paris Agreement, it does not fall behind the stringency of the 2020 Framework, as the abandoning of binding national targets for RE is balanced by strengthened obligations to prepare national plans, long-term strategies, and regular progress reports, as well as the enhanced monitoring and supervisory powers of the European Commission. While actual delivery will not least depend on how the Commission will use its established and newly acquired powers and tools, the 2030 Framework reinforces EU interest in strengthening international climate governance under the Paris Agreement.
\end{abstract}

\section{Keywords}

bindingness; climate governance; energy governance; Energy Union; European Union; Governance Regulation; hard governance; Paris Agreement; soft governance

Issue

This article is part of the issue "EU Energy Policy: Towards a Clean Energy Transition?", edited by Kacper Szulecki and Dag Harald Claes (University of Oslo, Norway).

(C) 2019 by the author; licensee Cogitatio (Lisbon, Portugal). This article is licensed under a Creative Commons Attribution 4.0 International License (CC BY).

\section{Introduction}

This article focuses on a key aspect of the effectiveness of EU (and indeed international) climate policy, namely the certainty that it will be able to achieve its ambitions. It is well established that the national climate action plans under the 2015 Paris Agreement on climate change (dubbed "Nationally Determined Contributions" -NDCs) and the objective of EU climate policy to reduce greenhouse gas (GHG) emissions by at least 40 per cent compared to 1990 levels by 2030 are insufficient. These plans and objective fail to put the world on a path towards averting dangerous anthropogenic climate change and limiting the increase of global average temperature to well below 2 or even $1.5^{\circ} \mathrm{C}$ as envisaged by Article 2 of the Paris Agreement (e.g., United Nations Environment Programme [UNEP], 2018). Much less attention has been paid to exploring how certain we can be that the established ambition will actually be delivered, with recent analyses reinforcing doubts in this respect (European Environment Agency [EEA], 2018; UNEP, 2018). This article aims to shed light on this issue by focusing on the features of policy frameworks which help ensure that established plans and targets will actually be implemented and achieved. Foundational for this thinking is the conceptualisation of the bindingness and stringency of par- 
ticular policies and policy frameworks along a soft-hard continuum, as further developed in Section 3.

Empirically, the article focuses on the EU's Climate and Energy Policy Framework consisting of a number of legislative instruments. In 2017/18 this Framework was updated and extended from the existing time-horizon of 2020 to 2030 in response to the international Paris Agreement, as discussed in Section 2. In order to assess how certain we can be that the ambitions of the 2030 Framework will be delivered, the stringency of governance embodied in this Framework is to be analysed. In approaching this question, identifying changes from the existing 2020 Framework seems useful, as it allows us to assess whether delivery has become more or less certain. In addition, the stringency of international climate governance under the Paris Agreement constitutes a valuable point of reference, as it puts EU climate and energy governance in a broader context.

The investigation thereby also aims to enhance clarity of existing debates on the stringency of EU climate and energy governance that have led to apparently contradictory findings. On the one side, research has in part held that EU energy governance has traditionally tended to be soft and that the 2030 Framework could harden this softness to some extent (Ringel \& Knodt, 2018; see also Szulecki, Fischer, Gullberg, \& Sartor, 2016). On the other side, the decision to abandon binding national targets for renewable energy (RE) in the 2030 Framework and to devise a new framework for EU climate and energy governance have fed concerns about a possible weakening of this governance (e.g., ClientEarth, 2016; MeyerOhlendorf, 2015; Meyer-Ohlendorf, Duwe, Umpfenbach, \& McFarland, 2014). Such concerns have been further nourished by the softening of international climate governance under the 2015 Paris Agreement which the 2030 Framework implements. By establishing clear and firm criteria for the bindingness/stringency of governance, this article attempts to provide a firm basis for clarifying and addressing these apparently contradictory findings. It thereby also holds potential for further research on European governance touching on aspects of soft and hard governance, such as research on the Open Method of Coordination (OMC) and "experimental governance" (de la Porte \& Pochet, 2012; Sabel \& Zeitlin, 2008, 2010; Trubek \& Trubek, 2005).

Against this backdrop, the article proceeds in three steps. First, Section 2 introduces the EU Climate and Energy Policy Framework as it evolved from 2020 to 2030, as well as the related international Paris Agreement on climate change concluded in 2015 . This is followed by the introduction of four key criteria for the bindingness of governance along the soft-hard continuum in Section 3 (formal status, nature of the obligations, prescriptiveness and precision, means for effecting accountability and effective implementation). Subsequently, Section 4 employs these key criteria to assess the bindingness of the 2030 Framework in comparison with the preceding 2020 Framework, and to contrast it to global climate gov- ernance under the Paris Agreement. The concluding part synthesises and discusses the results, including with respect to the aforementioned discussions.

Overall, I argue that the 2030 Framework features a relatively high level of bindingness and does not reduce the stringency of EU climate and energy governance compared to the 2020 Framework. However, it does modify the balance of the four dimensions of bindingness. Whereas binding national targets for RE are discontinued (nature of the obligations), obligations to prepare national plans, long-term strategies, and regular progress reports, as well as the monitoring and supervisory powers of the European Commission are significantly strengthened. While the 2030 Framework reinforces EU interest in strengthening international climate governance under the Paris Agreement, actual delivery will not least depend on how the Commission uses its established and newly acquired powers and tools.

\section{The EU's 2030 Climate and Energy Policy Framework and the Paris Agreement}

\subsection{Framework}

The EU's 2030 Climate and Energy Policy Framework builds on the preceding 2020 Framework. The 2020 Framework contains and implements three headline targets of 20 per cent for 2020: a 20 per cent GHG emission reduction, a 20 per cent share of RE in final energy consumption, and a 20 per cent improvement in energy efficiency (EE). While the first two targets are binding on member states (entailing specific differentiated national sub-targets), the EE target is indicative only. The 2020 Framework has been implemented through four key legislative instruments: three Directives (on the EU emissions trading system, RE and EE) and an "effort-sharing" decision on reduction targets for member states' GHG emissions outside the emissions trading system (Delbeke \& Vis, 2015; Jordan, Huitema, van Asselt, Rayner, \& Berkhout, 2010; Oberthür \& Pallemaerts, 2010). The 2018 analysis of the EEA suggests that the EU remains on track to overachieving its binding GHG emission reduction target for 2020 and has its binding RE target within reach, but may find it difficult to achieve its indicative $E E$ target (EEA, 2018).

The 2030 Framework updates and further develops the 2020 Framework. After the European Council defined the cornerstones of the 2030 Framework in October 2014 (European Council, 2014), the European Commission issued proposals for implementing legislative instruments in 2015 and 2016. The European Parliament and the Council of Ministers then amended and adopted these in 2017/2018. Accordingly, the following six legal acts form the core of the 2030 Framework:

- Directive (EU) 2018/410 amending Directive 2003/87/EC on the EU emissions trading system (the ETS Directive); 
- Regulation (EU) 2018/842 on binding annual GHG emission reductions by member states from 2021 to 2030 contributing to climate action to meet commitments under the Paris Agreement (the Effort-Sharing Regulation);

- Directive (EU) 2018/2001 on the promotion of the use of energy from renewable sources (the RE Directive);

- Directive (EU) 2018/2002 amending Directive 2012/ 27/EU on energy efficiency (the EE Directive);

- Regulation (EU) 2018/841 on the inclusion of GHG emissions and removals from land use, land use change and forestry in the 2030 climate and energy framework (the LULUCF Regulation);

- Regulation (EU) 2018/1999 on the governance of the Energy Union and climate action (the Governance Regulation).

This core is complemented by further legislative instruments not addressed in detail here, including Directive 2018/844 on the Energy Performance of Buildings, a Regulation on the electricity market (which awaits final adoption after agreement was reached in trialogue negotiations in December 2018) as well as several other pieces of legislation related to energy policy (see overview in Ringel \& Knodt, 2018). While a more comprehensive analysis of the legislation of the 2030 Framework is beyond the scope of this article, the following discussion focuses on the key features. Some further details relevant for the analysis of the stringency of governance are presented in Section 4.

The 2030 Framework upgrades and updates the three headline targets for 2030. Accordingly, the EU establishes a binding target of reducing its GHG emissions by at least 40 per cent from 1990 levels. This target is implemented through the ETS Directive and the EffortSharing Regulation. The ETS Directive determines a linear GHG emission reduction path declining by 2.2 per cent per year from 2021 to deliver a total reduction of 43 per cent below 2005 levels in 2030 in the ETS sectors (ETS Directive, revised Article 9). The Effort-Sharing Regulation obliges each member state to reduce its GHG emissions in the non-ETS sectors linearly towards a specific emission reduction target in order to deliver an overall EU emission reduction in these sectors of 30 per cent below 2005 levels in 2030. The EU's new RE target for 2030 is 32 per cent of final energy consumption and the new EE target is a 32.5 per cent improvement by 2030 . Both these targets were significantly increased in the legislative process from the 27 per cent targets the European Council agreed for each in 2014. The RE Directive defines a "binding (overall) Union target" (Articles 1 and 3), but it does not anymore contain binding targets for each individual member state. The EE target remains indicative ("headline target": Article 1 of the EE Directive).

The new LULUCF Regulation integrates the LULUCF sector, which was previously not covered, into the EU's Climate and Energy Policy Framework. It determines that each member state will have to ensure that LULUCF emissions do not exceed removals by the sector from 2021-2025 and from 2026-2030 (LULUCF Regulation, Article 4). On the basis of agreed accounting rules, each member state has to submit a national forestry accounting plan for the five-year periods 2021-2025 (by 2018) and 2026-2030 (in 2023) under Article 8 of the LULUCF Regulation.

The new Governance Regulation establishes an integrated framework for planning, reporting, and review related to the 2030 Framework (including other key elements of the Energy Union such as energy security). Building on related provisions in the existing $R E$ and $E E$ Directives, the Governance Regulation, in particular, requires each member state to submit in 2019, and every ten years thereafter, an integrated National Energy and Climate Plan (NECP). This plan is to include national contributions to the EU-wide RE and EE targets as well as related existing and planned policies and measures and is to be updated every five years (Articles 3, 9 and 14). Member states are also required to submit biennial progress reports on the implementation of their NECPs (Articles 17, 20-25), report biennially on policies and measures to implement their GHG emission target (Article 18) and annually on GHG emissions (Article 26). Member states also have to prepare, submit, and regularly update long-term strategies for climate and energy with a time horizon of at least 30 years (Article 15).

The Governance Regulation furthermore mandates the European Commission to monitor progress and take any remedial action (Articles 9 and 13, Chapter 5), assisted by the EEA (Article 42). In addition to regularly assessing overall progress by the EU as a whole, the Commission is to assess individual member states' plans and progress in their implementation, including the exante assessment of draft plans before they are finalised (Articles 9 and 13, Chapter 5). Where the Commission finds the overall ambition of plans or overall progress towards the relevant energy and climate targets to be insufficient, it is empowered/tasked to take targeted action in response. This includes recommendations to individual and/or all member states as well as proposing other measures (e.g., legislation) and exercising "its powers at Union level" (Articles 31 and 32). Member states whose progress on expanding RE is lagging are required to implement additional measures within one year to make up for the gap. Such additional measures may include contributing to an RE financing mechanism set up at Union level and need to be specified in the biennial progress reports (on the basis of which the Commission, in turn, can again issue recommendations) (Articles 32 and 33). Regarding overall progress, the Commission is to release a State of the Energy Union report annually (Article 35).

\subsection{The Paris Agreement on Climate Change}

Concluded in 2015, the Paris Agreement provides a new global framework for international climate governance 
under the UN Framework Convention on Climate Change. In contrast to the Kyoto Protocol which, for the EU and other developed countries, established binding emission targets, the Paris Agreement adopts a more procedural approach. While the Agreement has a comprehensive scope (including adaptation, finance, technology, capacity building and others), I focus on the approach to mitigation as the most relevant aspect for the EU's Climate and Energy Policy Framework.

In brief, the new approach to international governance of climate mitigation under the Paris Agreement can be crystallised in three main components. First, the Paris Agreement establishes and specifies clear overall targets and objectives for international climate governance. Article 2 determines the global temperature goal of "holding the increase of the global average temperature to well below $2^{\circ} \mathrm{C}$ above pre-industrial levels and pursuing efforts to limit the temperature increase to $1.5^{\circ} \mathrm{C}$ above pre-industrial levels". To this end, Article 4.1 further specifies that global net GHG emissions should reach zero "in the second half of this century". Second, the Paris Agreement establishes primarily procedural obligations to prepare, submit, maintain, and update NDCs and to report on emissions and the implementation of NDCs followed by a review of this information. Parties are obliged to "pursue domestic mitigation measures" towards their NDCs (Article 4.2), but they are not strictly required to achieve what they promised in their NDCs. Third, the Agreement sets up a regular cycle of review and revision to ratchet up efforts and increase ambition over time including a 5-yearly stocktake of past efforts (starting in 2023) as a basis for subsequent rounds of strengthening of NDCs (on the Paris Agreement, see Bodansky, 2016a; Doelle, 2016; Keohane \& Oppenheimer, 2016; Klein, Carazo, Doelle, Bulmer, \& Higham, 2017).

Finally, it is relevant to mention that, especially as a result of the EU's Governance Regulation, EU climate and energy governance and the Paris Agreement have become aligned in important respects. In particular, the five-year cycle of the submission/revision of NECPs is in line with the five-year cycle of review and revision under the Paris Agreement, as is annual reporting on emissions and biennial reporting on implementation progress. Both systems are furthermore directed at creating an upward dynamic (while preventing backtracking). Moreover, the requirement to prepare and submit long-term plans/strategies under the Governance Regulation implements the related requirement under Article 4.19 of the Paris Agreement. In addition, the review of RE and EE targets foreseen under Articles 3 of the respective EU Directives by 2023, fits with the international review of progress under the Paris Agreement to be undertaken in 2023.

\section{Assessing the Bindingness and Stringency of Governance: Four Criteria}

How can we assess the bindingness and stringency of particular regulations and governance frameworks? I sug- gest in the following a set of four criteria which are rooted in political science/governance but also informed by international and European law. Going beyond a narrower conception of formal legal bindingness (e.g., Bodansky, 2016b), the criteria are based on literature on hard versus soft law as well as the bindingness and legalisation of (international) governance (e.g., Abbott \& Snidal, 2000; Kalimo \& Staal, 2014; Keohane, Moravcsik, \& Slaughter, 2000; Oberthür \& Bodle, 2016; Shaffer \& Pollack, 2010; Trubek \& Trubek, 2005). Being generic, the criteria enable a differentiated and systematic assessment of the bindingness/stringency of both international and European governance frameworks. They are based on an understanding of softness and hardness (stringency) that is gradual rather than binary and aims at assessing governance rather than law as such.

\subsection{Formal Status}

The formal status of the rules on which a governance framework rests constitutes a first basic criterion for its bindingness (see the standard of "obligation" by Abbott \& Snidal, 2000). At stake is therefore whether governance is rooted in legal acts that are formally capable of establishing binding rules, rights/entitlements, and obligations. For example, in EU governance, the European Treaties, as well as Regulations, Directives and Decisions, are formally binding (see Article 288 of the Treaty on the Functioning of the European Union, TFEU). If requirements are not based on such binding instruments, actors will not strictly be legally obliged to adapt their behaviour accordingly. While formally non-binding instruments may still carry significant political weight and push actors to behavioural change, they also face significant limitations regarding accountability and legal implementation/enforcement (see below).

\subsection{Nature of Obligations}

Second, the substance of the "what" of the obligations is significant for the stringency of a governance framework. Particularly relevant in this respect is whether and to what extent any obligations directly address the substantive behaviour at stake or only indirectly relate to such behaviour without strictly requiring it to change. Some of the legal literature has introduced a distinction between "obligations of result" (e.g., an obligation to achieve a certain emission reduction) and "obligations of conduct" (e.g., an obligation to report on emissions). This distinction seems problematic, however, since some obligations of conduct can be rather substantive (e.g. an obligation to introduce a certain policy instrument such as a carbon tax). It may hence be more useful in our context to distinguish between "substantive" obligations that imply significant behavioural adaptations related to the problem at stake, such as reducing emissions or introducing/increasing a carbon tax, and purely "procedural" obligations which may at best only indirectly encour- 
age behavioural change, such as requirements to measure emissions, submit a report or prepare a plan (see discussion in Mayer, 2018; Oberthür \& Bodle, 2016).

\subsection{Prescriptiveness and Precision}

Third, how prescriptively and precisely rules establishing rights/entitlements and obligations are worded affects the actual bindingness of governance. The precision of a provision depends on how well defined the addressee (who), the substance (what), and the timeline (by when) are. Prescriptiveness depends on the discretion left to the subject of an obligation. In contrast to a clear-cut "shall" provision, the use of the word "should" leaves some discretion. Other ways to blur what the addressee is expected to do include the use of "may" or "could" or of expressions such as "to take into account", "encourage", "strive to", or the qualifications "as appropriate" and "as far as possible" (Abbott \& Snidal, 2000; Oberthür $\&$ Bodle, 2016). The precision and prescriptiveness of the relevant rules determine the clarity of what the subjects of these rules are expected, entitled, and required to do.

\subsection{Accountability and Effective Implementation (Including Enforcement)}

Last, but not least, it is important to consider the means available to promote and ensure accountability and effective implementation (including enforcement). In this respect, transparency (through monitoring and reporting) is a fundamental requirement. Without a minimum level of transparency of relevant actions and behaviour, even otherwise binding obligations may not "bite" in reality. In addition, mandating a dedicated body to oversee implementation and address implementation issues has been found to be of utmost importance in supporting effective implementation (Keohane et al., 2000). In this respect, the availability of effective measures to address deficiencies in implementation, including effective incentives and/or means of enforcement, seems particularly important (Bang, Hovi, \& Skodvin, 2016). Being able to hold the subjects of a rule to account for their implementation and compliance gives teeth to this rule and provides an important motivation for adapting behaviour accordingly.

\subsection{Four Meaningful Criteria Capturing Key Aspects of the Stringency of Governance}

There is, in principle, no correlation between the four dimensions and they can have varying scores along a gradual scale. Both formally binding and non-binding instruments can contain substantive and/or procedural requirements of varying precision and prescriptiveness with varying accountability and means for ensuring effective implementation attached. While the overarching framework in which rules and regulations are embedded affect these dimensions (see, for example, Sec- tion 4.4 below on the special enforcement powers under supranational EU law), the stringency of governance is hence not understood as binary (soft-hard, bindingnon-binding) but as gradual (see also Kalimo \& Staal, 2014). It is also difficult to establish trade-offs between the four dimensions. As a result, it is not easy to determine where soft governance ends and hard governance starts.

Taken together, these four criteria provide for a quite comprehensive, systematic, and differentiated conceptualisation of the bindingness/stringency of governance, including for comparative purposes. All four criteria are directly behaviourally relevant since they capture which behaviour is targeted and how strong the impetus is to adapt this behaviour accordingly. They depict key aspects that actors may employ to escape changing their behaviour: they could claim that the actual legal instrument as such (formal status) or a specific rule (prescriptiveness and precision) are not binding; they could also adapt procedures as required without changing the relevant substantive behaviour (nature of obligation), or they could neglect inconvenient obligations (accountability and effective implementation). Among the four criteria, the nature of obligations adds a new content element to previous accounts of softness and hardness (e.g., Keohane et al., 2000; see also Kalimo \& Staal, 2014). Overall, we may arguably expect that a higher score across the four dimensions may entail a higher degree of certainty of substantive behavioural effects.

\section{How Hard or Soft is the EU's 2030 Framework?}

This section applies the assessment framework developed above to the analysis of the EU's 2030 Framework as compared with the preceding 2020 Framework and the mitigation-related provisions of the international Paris Agreement. The comparison with the 2020 Framework enables us to identify whether EU climate and energy governance has become more or less stringent. International climate governance under the Paris Agreement can, due to the far-reaching differences between international and EU governance in general, and the approach of the Paris Agreement in particular (e.g., Bodansky, 2016a; Doelle, 2016; Klein et al., 2017; Oberthür \& Bodle, 2016), be expected to be comparatively soft. As such, it provides a useful contrast that helps put the stringency of EU climate and energy governance, and related changes, in perspective, and serves to illustrate the farreaching differences between international and supranational EU governance.

\subsection{Formal Status}

The 2030 Framework is firmly based on instruments of binding EU law. The legal acts that form the core of the 2030 Framework (see above) are Directives and Regulations that were proposed by the European Commission and subsequently adopted under the EU's "ordinary leg- 
islative procedure" by the European Parliament and the Council in 2018 in accordance with Articles 192 (environment) and/or 194 (energy) of the TFEU.

This aspect of the 2030 Framework is unchanged from the preceding 2020 Framework. The 2020 Framework was based on earlier versions of the ETS, RE and EE Directives as well as the 2009 Effort-Sharing Decision (Decision No 406/2009/EC), the predecessor of the Effort-Sharing Regulation (on the 2020 Framework, see Delbeke \& Vis, 2015; Jordan et al., 2010; Oberthür \& Pallemaerts, 2010). The new legal base of the RE and EE Directives-TFEU Article 194 on energy that was introduced in the 2009 Lisbon Treaty-does not change their formal legal status.

The formal status of the legal instruments of the 2030 Framework is also comparable to that of the Paris Agreement. In accordance with Article 2 of the 1969 Vienna Convention on the Law of Treaties, international treaties constitute instruments of international law that their parties are legally required to implement, much like EU member states (and others) are required to implement Regulations, Directives and Decisions. The 2015 Paris Agreement on climate change is an international treaty in this sense (on the legal nature of the Paris Agreement, see Bodansky, 2016b; Oberthür \& Bodle, 2016). That its formal legal status is thus comparable to the 2030 Framework is not meant to negate the crucial qualitative differences that exist between international and EU law (not least, direct effect, including on individuals, and qualitatively different means of enforcement) as also reflected in other criteria of bindingness addressed below (see especially Section 4.4 on accountability and effective implementation).

\subsection{Nature of Obligations}

The 2030 Framework combines substantive and procedural obligations in specific ways. As presented in Section 2 above, key substantive obligations are especially included in the ETS Directive and the Effort-Sharing and LULUCF Regulations. In addition, the RE and EE Directives, in particular, establish a number of further substantive requirements. These include obligations on member states to ensure 2020 RE targets are not undercut (Article 3.4) and that RE in transport reach 14 per cent by 2030 (Article 25) as well as relating to support schemes for renewables (Articles 4-6), renewable self-consumption and RE communities (Articles 21 and 22), RE in heating and cooling (Article 23), sustainability criteria for biofuels, bioliquids, and biomass (Article 26) as well as the verification of compliance with them (Article 30, all RE Directive) and annual energy savings of 1.5 per cent by 2030 , with various flexibilities (EE Directive, revised Article 7), among others. Key procedural components, as especially contained in the Governance Regulation, relate to NECPs, national forestry accounting plans, biennial and annual reports, and long-term strategies. Importantly, member states are required to specify their national contributions to the EU'S RE and EE targets in their NECPs and, where the Commission finds progress on RE to be lacking, to take additional measures within one year.

It is not clear whether the nature of the 2030 Framework's obligations is more or less stringent than the 2020 Framework. On one hand, binding national targets for the expansion of RE for individual member states have been discontinued. On the other hand, the accompanying procedural obligations have been significantly strengthened. Planning elements that were previously separate ( $R E, E E$, climate action) have been further improved and integrated into the NECPs, which enhances visibility; and a firm requirement for member states to prepare, submit, and regularly update long-term strategies has been introduced. Furthermore, as further discussed in the next section, an agreed formula allows national RE contributions to be determined for each member state in case the actions taken by member states do not add up to the EU's overall target of 32 per cent by 2030. Any member state that falls short in its progress is required to implement additional measures. Overall, the abandonment of national binding RE targets is hence significantly balanced by the introduction and strengthening of other elements.

Both the substantive and the procedural obligations under the 2030 Framework are significantly more stringent than those under the Paris Agreement. To start with, the significant substantive obligations of EU member states under the 2030 Framework (including quantitative targets) contrast with the Paris Agreement's nearly exclusive focus on procedural obligations, even if tuned towards agreed global goals (see Section 2.2 above). In addition, the Paris Agreement has fewer procedural obligations in comparison (related to NDCs and reporting and review; see Bodansky, 2016a, 2016b; Keohane \& Oppenheimer, 2016; Oberthür \& Bodle, 2016). As we will see in the next section, they also are much vaguer when compared to the 2030 Framework.

\subsection{Prescriptiveness and Precision}

The key substantive and procedural obligations of the 2030 Framework generally score highly on prescriptiveness and precision. The aforementioned obligations and quantitative targets under the ETS Directive, the EffortSharing Regulation and the LULUCF Regulation are well defined. Specific dates for the submission of draft, updated, and final NECPs, national forestry accounting plans, long-term strategies, biennial reports, and annual reports are determined. Guidance on the information these plans and reports have to contain and the methodologies which have to be applied, where relevant, is detailed.

Several flexibilities granted in the 2030 Framework limit its prescriptiveness without undercutting it. The ETS Directive allows free allocation of emission allowances to industries in international competition and to power plants in certain (central and eastern European) mem- 
ber states. The Effort-Sharing Regulation permits (limited) banking and borrowing, transfer of emissions reductions between member states, and off-setting with ETS allowances as well as with GHG removals in the LULUCF sector up to a defined maximum (Articles 5-7 and Annexes II and III). The LULUCF Regulation also provides some flexibility, including the possibility of banking net emission removals for subsequent years and transferring them between member states (Articles 11-13). The RE Directive furthermore allows member states to engage in statistical transfers and joint projects with each other and with third countries in order to achieve their national contributions (Articles 8-12). Other substantive requirements of the RE and EE Directives also introduce flexibilities. Overall, these flexibilities soften the prescriptiveness of the well-defined obligations in a limited and clearly defined way.

Similarly, a number of ambiguities soften some obligations to some extent without abandoning them. Prominently, the RE and EE Directives do not contain national $\mathrm{RE}$ and $\mathrm{EE}$ targets for member states but only define Union-wide targets for 2030 (Article 3 RE Directive; Article 1 EE Directive). Similarly, the Governance Regulation allows member state contributions to the EU targets for RE and EE to be based on loosely defined "national/relevant circumstances" (including, in the case of $\mathrm{RE}$, "early efforts") to be explicated in NECPs (Articles 5 and 6). The other aforementioned substantive requirements of the RE and EE Directives on support schemes for RE etc. also introduce ambiguities at times, including with respect to the annual energy savings target of 1.5 per cent and the increase of RE in heating and cooling. Overall, however, the ambiguities remain limited in number and scope.

The 2030 Framework has both strengthened and weakened the prescriptiveness and precision of the preceding 2020 Framework. Many of the flexibilities and ambiguities included in the 2030 Framework already exist in the 2020 Framework. However, the abandonment of binding national RE targets and the extension of flexibilities member states enjoy under the Effort-Sharing Regulation (regarding LULUCF and ETS allowances) in particular, even though well defined, have weakened precision and prescriptiveness. In contrast, requirements relating to plans, progress reports, and the long-term strategy have become much more precise with the Governance Regulation (compare the relevant provisions in the Governance Regulation with the pre-existing requirements in the 2009 RE Directive 2009/28/EC, especially Article 22, and the 2012 EE Directive 2012/27/EU, especially Article 24 and Annex XIV; see also Article 15 and Annex IV of the Governance Regulation). Importantly, the Regulation contains a detailed formula for calculating each member state's fair share of the EU RE target of 32 per cent for 2030 (Article 5 and Annex II). The Commission is required to use this formula as a reference where the aggregate contributions of the member states fall short of the EU target (Article 31.2). While not containing national RE targets, the Governance Regulation hence allows such targets to be derived for each member state. These only come into play formally if individual contributions are insufficient, but they may well provide guidance to member states in designing their contributions and serve as a more general point of reference. On balance, the 2030 Framework has hence hardly weakened the prescriptiveness and precision of EU climate and energy governance.

In comparison, the Paris Agreement is much less prescriptive and precise overall. Its largely procedural obligations are fewer and more discretionary than those of the Governance Regulation, e.g. by leaving the structure and content of NDCs largely up to each party (Keohane \& Oppenheimer, 2016; Oberthür \& Bodle, 2016; United Nations Framework Convention on Climate Change [UNFCCC], 2018). This contrasts with the much higher number of precise obligations for each member state under the EU's 2030 Framework relating to the ETS, the non-ETS sectors, the LULUCF sector, the preparation and submission of NECPs and long-term strategies, and various aspects of RE and EE (see above).

\subsection{Accountability and Effective Implementation (Including Enforcement)}

Both the general EU governance framework and the 2030 Framework itself, in particular, the Governance Regulation, provide significant means supporting accountability and effective implementation. Hence, failure to implement legal obligations arising from the 2030 Framework (see above) can in principle be subject to infringement proceedings in accordance with Articles 258-260 of the TFEU (involving the Commission and the Court of Justice of the EU with the possibility of penalty payments). To the extent that it has "direct effect", EU law can furthermore to a significant extent be enforced through the national courts of the member states (Craig \& de Búrca, 2015, especially Chapters 7 and 8). It is here that the embedding of EU climate and energy governance in the overarching supranational order of the EU matters most. In addition, the Governance Regulation not only enhances transparency through planning and reporting by member states but also mandates the European Commission to monitor implementation and take remedial action, as elaborated in Section 2.1 above.

As such, the 2030 Framework maintains a high level of support for effective implementation and enforcement (compared to the 2020 Framework). On one hand, infringement proceedings under Articles $258-260$ can no longer be employed to enforce national RE targets, as these targets have been abandoned. On the other hand, the Governance Regulation introduces an obligation for member states to take corrective action where their efforts towards the EU-wide RE target of 32 per cent for 2030 fall short. Even though form and content of such corrective action are left to each member state, failure to take effective action can in principle lead to in- 
fringement proceedings. In addition, the integration of planning and reporting across the different dimensions of the "Energy Union" enhances transparency and accountability, and the monitoring and enforcement powers of the Commission have been strengthened (ex-ante assessment of plans, Commission recommendations). Member states are now required to take "due account" of Commission recommendations (Article 34.2), to report on their follow-up and provide justification in case they do not act upon these recommendations. On balance, accountability and effective implementation can hardly be said to have suffered from the 2020 to the 2030 Framework.

These arrangements for promoting accountability and effective implementation are significantly more stringent than those under the Paris Agreement. The differences are particularly pronounced with respect to available response measures and, to a lesser extent, monitoring of implementation. The Paris Agreement in its Article 13 and its further implementing provisions (UNFCCC, 2018) requires parties to report on GHG inventories and the implementation of NDCs in a similar way as, but in less detail than, the Governance Regulation does for EU member states. It also foresees technical reviews of such reports by teams of technical experts. However, there is no review of the ambition of NDCs and the review of implementation is limited because achieving/implementing NDCs is not a legal requirement. Recommendations on NDCs and their implementation are not provided for and the mechanism for facilitating implementation and ensuring compliance under Article 15 of the Agreement will focus on particular problems rather than assessing implementation of each and every party (as the Commission is mandated to do under the Governance Regulation). Furthermore, the mechanism will only have soft, facilitative measures available (see Bang et al., 2016; Klein et al., 2017; Oberthür \& Northrop, 2018; UNFCCC, 2018).

\section{Discussion and Conclusions}

The EU's 2030 Framework scores relatively highly on the four dimensions of governance stringency and bindingness distinguished here (see Table 1). It is based on binding EU legal acts, namely various Regulations and Directives, and establishes both significant substantive and procedural obligations/requirements. While the Framework does leave considerable degrees of discretion to member states, this is not unusual for EU legislation (and indeed immanent in the instrument of EU Directives) and this discretion is confined in important ways. Furthermore, the governance framework and its embedding in broader supranational EU governance structures provide for high levels of accountability and effective implementation. Various obligations under the Framework are generally suitable for the European Commission to initiate infringement proceedings in case of there being a lack of implementation. In addition, the Governance Regulation mandates the European Commission to follow up with each member state on its planning and reporting and provides specific means for the Commission to advance implementation (including recommendations).

The 2030 Framework differs slightly from its predecessor, the 2020 Framework, but these changes, on balance, do not make EU climate and energy governance less stringent or less binding (see also Table 1). On the downside, binding national RE targets became lost in the 2030 Framework and some new flexibilities give additional, though limited room for member states to cushion the required behavioural changes. On a more positive side, however, member states' procedural obligations to prepare energy and climate plans and long-term strategies as well as to report on progress in implementation have been strengthened, as have the aforementioned powers of the European Commission to monitor and promote implementation. Furthermore, the Governance Regulation contains a formula that, in the absence

Table 1. Stringency of climate/energy governance frameworks.

\begin{tabular}{lccc}
\hline Dimension & EU 2030 & EU 2020 & Paris Agreement \\
\hline Formal status & $\begin{array}{c}\text { high } \\
\text { (binding EU legal acts) }\end{array}$ & $\begin{array}{c}\text { high } \\
\text { (binding EU legal acts) }\end{array}$ & $\begin{array}{c}\text { high } \\
\text { (international treaty) }\end{array}$ \\
\hline $\begin{array}{l}\text { Nature of } \\
\text { obligation }\end{array}$ & $\begin{array}{c}\text { medium-high } \\
\text { (substantive \& enhanced } \\
\text { procedural requirement, incl. } \\
\text { binding emission targets) }\end{array}$ & $\begin{array}{c}\text { medium-high } \\
\text { (substantive \& procedural } \\
\text { requirement, incl. binding } \\
\text { targets for emissions and RE) }\end{array}$ & $\begin{array}{c}\text { low } \\
\text { (procedural requirements) }\end{array}$ \\
\hline $\begin{array}{l}\text { Prescriptiveness } \\
\text { and precision }\end{array}$ & $\begin{array}{c}\text { medium-high } \\
\text { (precise obligations with } \\
\text { limited ambiguities/ } \\
\text { flexibilities) }\end{array}$ & $\begin{array}{c}\text { medium-high } \\
\text { (precise obligations with } \\
\text { limited ambiguities/ } \\
\text { flexibilities) }\end{array}$ & $\begin{array}{c}\text { low-medium } \\
\text { (high degree of discretion) }\end{array}$ \\
\hline $\begin{array}{l}\text { Accountability } \\
\text { and } \\
\text { implementation }\end{array}$ & $\begin{array}{c}\text { high } \\
\text { (reporting, enhanced follow-up } \\
\text { by COM, infringements) }\end{array}$ & $\begin{array}{c}\text { high } \\
\text { (reporting, limited follow-up } \\
\text { by the COM, infringements) }\end{array}$ & $\begin{array}{c}\text { (reporting, expert review, } \\
\text { facilitative response measures) }\end{array}$ \\
\hline
\end{tabular}

Source: own assessment based on Section 4 (see there for further detail). 
of national RE targets, allows national RE shares to be determined for each member state, in the event that aggregate ambitions of member states are insufficient for the collective target of 32 per cent by 2030 . Overall, a limited loss of substantive obligations is balanced by gains in procedural obligations and powers to promote effective implementation.

Differences between this assessment of EU climate and energy governance and others may in part result from the specific set of criteria systematically applied here. In contrast to the above assessment, others have likened current EU energy governance to the OMC, arguing that it is soft and that the 2030 Framework, especially its Governance Regulation, amount to "'harder' soft governance" (Ringel \& Knodt, 2018, p. 215, see also p. 219). Part of the difference may arise because the assessment put forward here goes beyond energy governance in the strict sense, taking an integrated view of EU energy and climate governance. Such an integrated view is immanent in the 2030 Framework and the EU's Energy Union project and enshrined in the overarching Governance Regulation which has a double legal base and covers both aspects. Perhaps more importantly, the fourdimensional conceptualisation of the stringency of governance along the soft-hard continuum advocated here goes beyond an analysis focusing-implicitly-on procedural aspects. In this context, the contrast with the international Paris Agreement illustrates the relative stringency of the EU governance framework. Overall, the systematic and differentiated approach to assessing governance stringency pursued here, based on explicit criteria that capture key aspects of bindingness, enables an encompassing and fine-grained appraisal and can hopefully facilitate future debate on how to measure and evaluate the stringency of governance.

The prospect for delivery of the EU's 2030 targets for climate and energy hence remains strong. The 2020 Framework has, even without significant recourse to infringement proceedings, led to significant adaptations of member state policies and industry behaviour. As a result, the EU remains on track to overachieving its binding GHG emission reduction target for 2020 and has its binding RE target within reach (while successful achievement of its indicative EE target remains uncertain) (EEA, 2018). Admittedly, more factors than simply the stringency of the governance framework affect whether or not the EU will succeed in achieving its strengthened 2030 targets. However, the 2030 Framework builds on the proven 2020 Framework and introduces further means to promote delivery, especially by further strengthening the role of the European Commission, as mentioned above. Whether this will be sufficient to ensure actual delivery will not least depend on how the Commission uses the powers and tools it has received (in addition to those it continues to have at its disposal under the EU Treaties).

It may not be surprising that EU climate and energy governance under the 2030 Framework, therefore, remains much "harder" than international climate gover- nance under the Paris Agreement (see Table 1). While the formal status of the relevant legal instruments is similar, the nature of the obligations, their prescriptiveness and precision, and the means available for promoting accountability and effective implementation differ widely. The Paris Agreement primarily establishes procedural obligations to prepare and submit national climate plans in the form of NDCs and to report on emissions and NDC implementation subject to expert review. In contrast, the 2030 Framework establishes both various substantive and procedural obligations, with the latter going far beyond the Paris Agreement. The 2030 Framework's requirements are also much more prescriptive and precise than the Paris Agreement and are backed up by far stronger mechanisms for promoting accountability and effective implementation led by the European Commission.

This raises the question of why the EU, although updating its climate and energy governance towards 2030 to implement the Paris Agreement, did not weaken it in light of this Agreement. Whereas the EU was obliged to achieve its GHG emission target under the Kyoto Protocol, the Paris Agreement lacks a similar substantive international obligation (see Section 2). While this article has not investigated the factors that may help us explain the continued stringency of EU climate and energy governance, we may consider that there are strong forces within the EU that support such continued stringency. They include significant interests in the continued promotion of RE and $\mathrm{EE}$, the status of climate and energy governance as a domestic and international signature issue for the EU, the supranational system of EU governance built on "the rule of law" as a whole, and general path dependency favouring continuity and incremental change. As long as these forces remain in place, they may also drive the development of EU climate and energy policy beyond 2030. One important implication is that-since the implementation of the Paris Agreement so far relies nearly exclusively on domestic delivery systems and hence remains highly vulnerable to related shortcomings-the EU continues to have a strong interest in strengthening international climate governance as well.

\section{Acknowledgments}

This article has been prepared in the context of the Jean Monnet Network “Governing the EU's Climate and Energy Transition in Turbulent Times" (GOVTRANwww.govtran.eu) with the support of the Erasmus+ programme of the European Union. The Research Council of Norway has also contributed through the Large-scale Programme for Energy Research ENERGIX (REMIX, project no. 243756). I would like to thank Ingmar von Homeyer and two anonymous reviewers for helpful comments.

\section{Conflict of Interests}

The author declares no conflict of interests. 


\section{References}

Abbott, K. W., \& Snidal, D. (2000). Hard and soft law in international governance. International Organization, 54(3), 421-456.

Bang, G., Hovi, J., \& Skodvin, T. (2016). The Paris Agreement: Short-term and long-term effectiveness. Politics and Governance, 4(3), 209-218.

Bodansky, D. (2016a). The Paris climate change agreement: A new hope? The American Journal of International Law, 110(2), 288-319.

Bodansky, D. (2016b). The legal character of the Paris Agreement. Review of European, Comparative \& International Environmental Law (RECIEL), 25(2), 142-150.

ClientEarth. (2016). Key features of credible Energy Union governance. London: ClientEarth. Retrieved from https://www.documents.clientearth.org/wp-content/ uploads/library/2016-01-10-key-features-of-credible -energy-union-governance-ce-en.pdf

Craig, P., \& de Búrca, G. (2015). EU law. Text, cases, and materials (6th ed.). Oxford: Oxford University Press.

De la Porte, C., \& Pochet, P. (2012). Why and how (still) study the open method of co-ordination (OMC)? Journal of European Social Policy, 22(3), 336-349.

Delbeke, J., \& Vis, P. (Eds.). (2015). EU climate policy explained. Abingdon: Routledge.

Doelle, M. (2016). The Paris Agreement: Historic breakthrough or high stakes experiment? Climate Law, $6(1 / 2), 1-20$.

European Council. (2014). Conclusions, document EUCO 169/14, 23 and 24 October. Brussels: European Council.

European Environment Agency. (2018). Trends and projections in Europe 2018. Tracking progress towards Europe's climate and energy targets. Luxembourg: Publications Office of the European Union.

Jordan, A., Huitema, D., van Asselt, H., Rayner, T., \& Berkhout, F. (Eds.). (2010). Climate change policy in the European Union: Confronting the dilemmas of mitigation and adaptation? Cambridge: Cambridge University Press.

Kalimo, H., \& Staal, T. (2014). "Softness" in international instruments: The case of transnational corporations. Syracuse Journal of International Law and Commerce, 41(2), 259-334.

Keohane, R. O., Moravcsik, A., \& Slaughter, A. M. (2000). Legalized dispute resolution: Interstate and transnational. International Organization, 54(3), 457-488.

Keohane. R. O., \& Oppenheimer, M. (2016). Paris: Beyond the climate dead end through pledge and review? Politics and Governance, 4(3), 142-151.

Klein, D., Carazo, M. P., Doelle, M., Bulmer, J., \& Higham, A. (Eds.). (2017). The Paris Agreement on climate change: Analysis and commentary. Oxford: Oxford University Press.

Mayer, B. (2018). Obligations of conduct in the international law on climate change: A defence. Review of
European, Comparative \& International Environmental Law (RECIEL), 27(2), 130-140.

Meyer-Ohlendorf, N. (2015). An effective governance system for 2030 EU climate and energy policy: Design and requirements (Discussion paper). Ecologic: Berlin. Retrieved from https://www.ecologic. eu/sites/files/publication/2015/meyer-ohlendorf-15 -effective-governance-syystem-2030.pdf

Meyer-Ohlendorf, N., Duwe, M., Umpfenbach, K., \& McFarland, $\mathrm{K}$ (2014). The next EU climate and energy package-EU climate policies after 2020. Berlin: Ecologic. Retrieved from https://www.ecologic.eu/sites/ files/publication/2014/eu_climate_energy_package_ study_2014.pdf

Oberthür, S., \& Bodle, R. (2016). Legal form and nature of the Paris outcome. Climate Law, 6(1/2), 40-57.

Oberthür, S., \& Northrop, E. (2018). Towards an effective mechanism to facilitate implementation and promote compliance under the Paris Agreement. Climate Law, 8(1/2), 39-69.

Oberthür, S., \& Pallemaerts, M. (2010). The EU's internal and external climate policies: An historical overview. In S. Oberthür \& M. Pallemaerts (Eds.), The new climate policies of the European Union: Internal legislation and climate diplomacy (pp. 27-63). Brussels: VUB Press.

Ringel, M., \& Knodt, M. (2018). The governance of the European Energy Union: Efficiency, effectiveness and acceptance of the winter package 2016. Energy Policy, 112, 209-220.

Sabel, C. F., \& Zeitlin, J. (2008). Learning from difference: The new architecture of experimentalist governance in the EU. European Law Journal, 14(3), 271-327.

Sabel, C. F., \& Zeitlin, J. (Eds.). (2010). Experimentalist governance in the European Union. Towards a new architecture. Oxford: Oxford University Press.

Shaffer, G. C., \& Pollack, M. A. (2010). Hard vs. soft law: Alternatives, complements, and antagonists in international governance. Minnesota Law Review, 94, 706-799.

Szulecki, K., Fischer, S., Gullberg, A. T., \& Sartor, O. (2016). Shaping the "Energy Union": Between national positions and governance innovation in EU energy and climate policy. Climate Policy, 16(5), 547-567.

Trubek, D. M., \& Trubek, L. G. (2005). Hard and soft law in the construction of social Europe: The role of the open method of co-ordination. European Law Journal, 11(3), 343-364.

United Nations Environment Programme. (2018). The emissions gap report 2018. Nairobi: United Nations Environment Programme.

United Nations Framework Convention on Climate Change. (2018, December 20). Decisions adopted at the climate change conference in Katowice, Poland, 2-14 December 2018. United Nations Framework Convention on Climate Change. Retrieved from https://unfccc.int/katowice 


\section{About the Author}

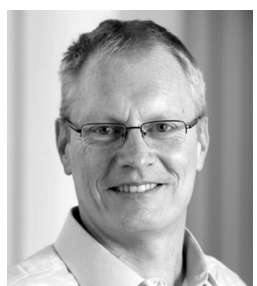

Sebastian Oberthür is Professor of Environment and Sustainable Development at the Institute for European Studies (IES) at the Vrije Universiteit Brussel. Between 2005 and 2015, he also served as the IES Academic Director. Since the early 1990s, Sebastian has contributed to scholarship on a broad range of issues relating to international and European environmental, climate and energy governance, including the international role of the European Union in this field. 